\title{
Fatal acute pancreatitis following sclerosis of a bleeding duodenal ulcer complicated by an intramural duodenal hematoma
}

\author{
João Dinis Silva, Nuno Veloso, Rogério Godinho, Lurdes Gonçalves, Isabel Medeiros and Celeste Viveiros \\ Department of Gastroenterology. Hospital do Espírito Santo de Évora EPE. Portugal
}

\section{CASE REPORT}

An 80-year-old male was admitted with generalized weakness, pale skin and tarry stools. He had a past medical history of atrial fibrillation on anticoagulant therapy (warfarin) and osteoarthritis requiring more than occasional non-steroidal anti-inflammatory drugs. His blood pressure was 154/65 $\mathrm{mmHg}$ and he had no abdominal tenderness. Significant laboratory results showed: hemoglobin $9.4 \mathrm{~g} / \mathrm{dl}$, international normalized ratio (INR) 3.84, blood urea $141 \mathrm{mg} / \mathrm{dl}$ and creatinine $1.2 \mathrm{mg} / \mathrm{dl}$. Upper endoscopy revealed an oozing ulcer at the bulbar apex (Forrest classification IB) that was treated with epinephrine $(10 \mathrm{ml}$ at 1:10,000) and polidocanol $(5 \mathrm{ml}$ at $1 \%$ ) injection (Fig. 1). Warfarin was stopped and intravenous proton pump inhibitors initiated. After $24 \mathrm{~h}$, he started to complain of progressively increasing epigastric pain. A drop in hemoglobin concentration to $6 \mathrm{mg} / \mathrm{dl}$, a prolongation of the INR to 4.05, an elevated amylase (2,491 U/L) and lipase $(16,100 \mathrm{U} / \mathrm{L})$ were noted. He was transfused with two units of packed RBC. On abdominal ultrasound (US) no particular finding as to the cause of the pancreatitis was found. However, the abdominal complaints worsened and on day 3 an abdominal CT revealed pancreatic head edema, inflammatory changes in the peripancreatic fat and a huge intramural duodenal hematoma $(14 \times 6 \mathrm{~cm})$ that involved the second portion of the duodenum and was associated with free peritoneal fluid and air (Fig. 2). Returning from the CT scan, the patient suffered cardiac arrest and died in spite of our best efforts to resuscitate him.

\section{DISCUSSION}

The main cause of intramural duodenal hematoma (IDH) is abdominal trauma, which in adults accounts for more than $70 \%$ of cases. Blood dyscrasias, anticoagulant therapy and to a lesser degree, duodenal biopsy, injection therapy for bleeding peptic ulcer or pancreatic disease are responsible for the rest of the cases $(1,2)$. Presently, warfarin toxicity is

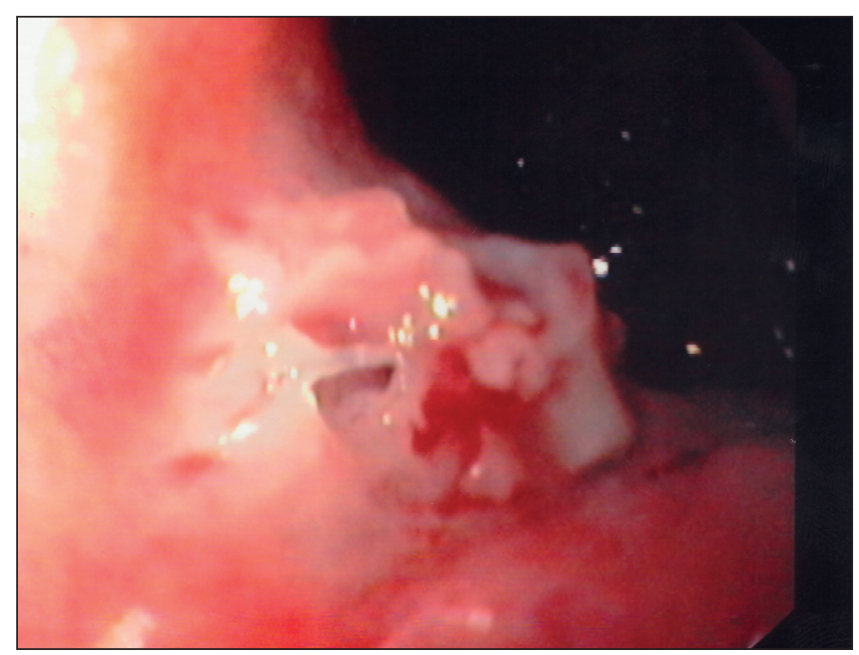

Fig. 1. Oozing duodenal ulcer at the bulbar apex efficiently treated with the injection of 10 cc of adrenaline $(1: 10,000)$ and 5 cc of polidocanol $(1 \%)$.

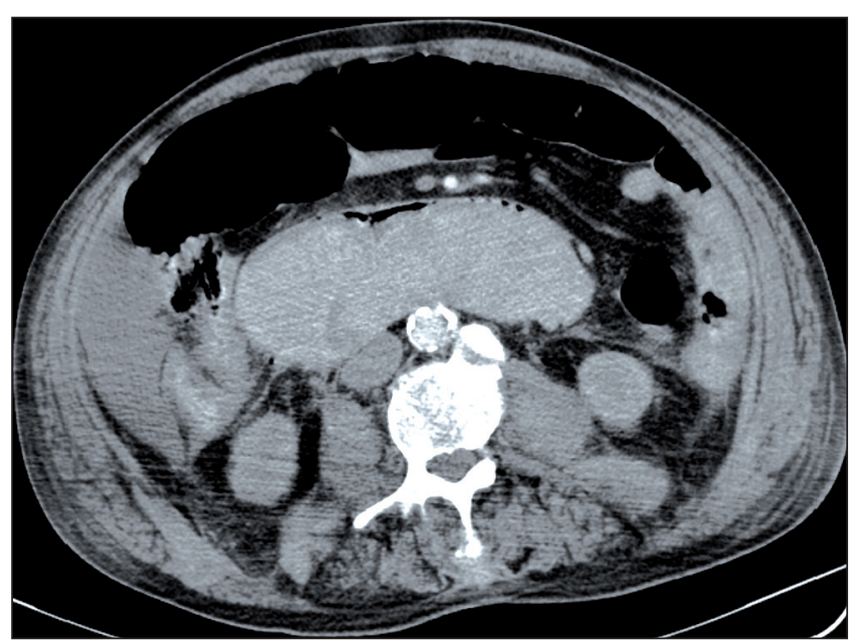

Fig. 2. Abdominal $C T$ image revealing a huge intramural duodenal hematoma $(14 \times 6 \mathrm{~cm})$ that probably caused pancreatitis and wall perforation. 
the most common cause of spontaneous intramural small-bowel hematoma (3). This type of complication after endoscopic treatment of bleeding ulcers occurs most often with the use of epinephrine, polidocanol and fibrin tissue adhesive, especially in patients with some kind of disturbance of the coagulation parameters (4). Hemostatic clips do not seem to have a protective role (5). Current recommendations suggest INR correction if the values are supratherapeutic because it facilitates endoscopic treatment (6) but the admission INR does not seem to impact on patient outcomes such as mortality, transfusions, need for hemostasis, or rebleeding (7). Acute pancreatitis as been described as a consequence of IDH when there is duodenal papilla obstruction by the hematoma $(1,2)$. Abdominal US is an excellent screening modality (8) but abdominal CT is the imaging technique of choice both for the diagnosis and for the exclusion of complications such as acute pancreatitis or perforation (9). In conclusion, maximal awareness for intramural hematoma is required as it is a potential complication of duodenal endoscopic hemostasis and in these occasions strong effort should be placed at optimizing patient coagulation parameters before endoscopy. In addition, our case illustrates two rare and ultimately fatal occurrences that are the development of acute pancreatitis and duodenal wall perforation secondary to the intramural hematoma.

\section{REFERENCES}

1. Shiozawa K, Watanabe M, Igarashi Y, Matsukiyo Y, Matsui T, Sumino Y. Acute pancreatitis secondary to intramural duodenal hematoma: Case report and literature review. World J Radiol 2010;2:283-8.

2. Fukunaga N, Ishikawa M, Yamamura Y, Ichimori T, Sakata A. Spontaneous intramural duodenal hematoma complicating acute pancreatitis. Surgery 2011;149:143-4.

3. Maher AA, Collins JM, Olden KW, Kelly KA. Spontaneous intramural small-bowel hematoma: Clinical presentation and long-term outcome. Arch Surg 2002;137:306-10

4. Sugai K, Kajiwara E, Mochizuki Y, Noma E, Nakashima J, Uchimura K, et al. Intramural duodenal hematoma after endoscopic therapy for a bleeding duodenal ulcer in a patient with liver cirrhosis. Internal Medicine 2005;44:954-7.

5. Yen HH, Chen YY. Duodenal intramural hematoma and delayed perforation: rare but fatal complication of endoscopic therapy for a bleeding duodenal ulcer. Endoscopy 2009; 41 (Supl. 2): E119.

6. Barkun AN, Bardou M, Kuipers EJ, Sung J, Hunt RH, Martel M, et al. International consensus recommendations on the management of patients with nonvariceal upper gastrointestinal bleeding. Ann Inter Med 2010;152:101-13.

7. Karsan SS, Kanwal F, Nordstrom C, Huang ES, Singh IM, Makhani MD, et al. The impact of elevated INR on outcomes in GI hemorrhage [Abstract]. Gastroenterology 2010;138:S-89.

8. Hou SW, Chen CC, Chen KC, Ko SY, Wong CS, Chong CF. Sonographic diagnosis of spontaneous intramural small bowel hematoma in a case of warfarin overdose. J Clin Ultrasound 2008;36:374-6.

9. Diniz-Santos DR, Cairo RCA, Braga H, Araujo-Neto C, Paes IB, Silva LR. Duodenal hematoma following endoscopic duodenal biopsy: A case report and review of the literature. Can J Gastroenterol 2006;20:39-42. 